\title{
Research on Hybrid Teaching Mode Innovation In Applied Undergraduate Colleges and Universities \\ -- Taking Train Operation Control System as an Example
}

\author{
Jingqiu Yang \\ Jilin Teachers'Institute of Engineering and Technology, Changchun,Jilin , China \\ 495557310@qq.com
}

Keywords: Internet +; Hybrid teaching; Flipped classroom; Blue ink cloud class

\begin{abstract}
Pick to compared with the traditional teaching model, hybrid teaching based on constructivism learning theory, due to the rapid development of technical advantage, but based on hybrid flip class, class, class teaching model research focused on the definition, nature, hindering factors analysis, and many other aspects, at present there is still a network combined with the surface of the education, lack of substance separation, interaction, etc. Taking the course "train operation control system" as an example and with the help of blue ink cloud class mobile teaching software, this paper introduces the construction and implementation of hybrid teaching mode, and constructs an open and interactive teaching environment for learners from the aspects of preliminary analysis, activity and resource design, learning evaluation design and so on. The practice shows that this model has a positive effect on the improvement of students' academic performance and interest.
\end{abstract}

\section{Foreword}

Under the guidance of the concept, the "Internet + education" teaching has been widely implemented in universities, and the curriculum reform under "Internet + education" has been gradually deepened. In the reform of teaching mode, jilin engineering and technology normal university has introduced the mobile course software of the class platform of blue ink cloud to realize students' independent learning after class. The assistance of software and the teaching in class form a new teaching mode of exploring difficult problems in class, testing, discussion, communication, demonstration and evaluation in class, completing homework and expanding reading after class, and realizing the personalized learning needs of students.

\section{Construction of mixed teaching mode based on blue and black cloud classes}

Blueink cloud class is a mobile teaching software based on the Internet environment. With the help of the software, teachers can carry out various forms of classroom teaching activities in large classes, extending the teaching form from class to class and enabling students to learn independently and interact with teachers and students in real time. Realize the teaching behavior, via the Internet learning behavior of large data records, further improving the system of incentive and evaluation, students' learning evaluation experience the charm of the value system, the teachers teaching evaluation system, to achieve the process evaluation and individual evaluation of the teaching, improve teachers' teaching ability, and provide the technical support for students learning effect [2]. This paper constructs a hybrid teaching model framework based on blue and black cloud classes, as shown in figure 1 . The whole teaching design includes three stages: preliminary analysis, activity and resource design, and learning evaluation design, among which activity and resource design are the stages that can best embody the mixed learning characteristics. The preliminary analysis stage includes four aspects: teaching objective analysis, teaching content analysis, learner analysis and mixed teaching environment analysis. Activity and resource design includes learning resource design, teaching strategy formulation and teaching activity design. Learning evaluation 
design is judged by learning process evaluation, course evaluation and activity rticipation evaluation[3].

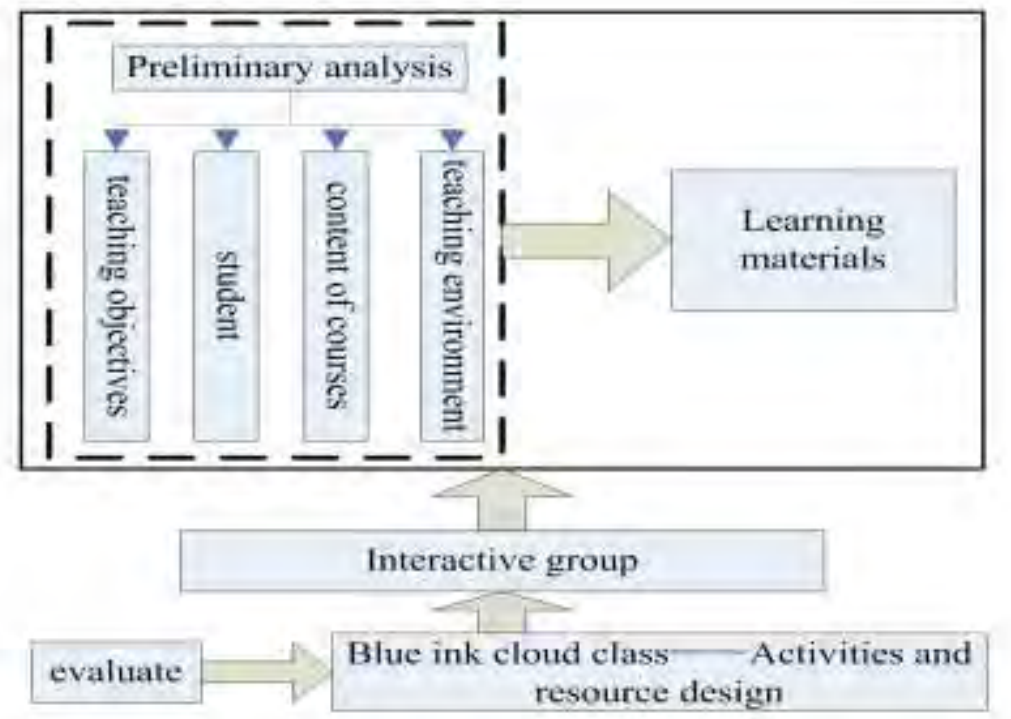

Figure 1. mplementation of the mixed teaching mode based on the blue and black cloud class

\section{Implementation of hybrid teaching mode}

Classroom implementation. This paper takes train operation control system as a practical case of mixed teaching mode. Two classes, class A and class B, were selected as the objects of comparison, including 50 students in class A and 45 students in class B, respectively adopting mixed teaching mode and traditional teaching mode. Divide each class into 10 groups.

Preliminary analysis. Early analysis refers to the teaching design and strategy choice before the preparation of teachers under the background of "Internet + " hybrid teaching goal is based on the characteristics of the era background, cultivate learners' access to information, comprehensive literacy such as information processing ability, cooperation ability, meet the social demand for comprehensive talent in the 21 st century. Through the analysis of the teaching objectives and the adoption of appropriate teaching methods, the learners can clarify the teaching objectives and the natural state after the occurrence of teaching activities. Through the analysis of students' basic situation and course teaching content, we can judge whether it is suitable for hybrid teaching and to what degree. Class two students have completed the orbit transportation communication signals base "course, master the structure and basic principle of the communication system of rail transit, students generally reflect the train operation control system course is difficult to grasp and understanding, because this course is a professional core courses, with future professional courses of study are more important, so need to strengthen the teachers guide, improving the students' learning interest and motivation.

Dividing learning units. With the help of the blue ink cloud class, and combined with the characteristics of the class to analyze the learning situation, according to the teaching objectives

To analyze the teaching content and adjust the teaching content according to the standards, subject characteristics and students' cognitive rules. The learning resources are divided into small learning units and the teaching objectives, methods and strategies of each unit are determined. All learning resources are uploaded by the teacher through the mobile teaching software terminal for learners to learn. Meanwhile, students' utilization of learning resources is recorded through the background of the software, so that the teacher can know students' learning situation in real time and interact with them.

Design of teaching strategies. Teaching strategies are the focus of the whole teaching activities, which are mainly used to solve the problems of how teachers teach and how students learn, including the teaching methods, teaching means, teaching forms, teaching sequence and teaching media adopted in the process of teaching implementation. The teaching strategies are also different for different teaching contents, teaching objects and teaching objectives. For example, the leading organizer strategy is a kind of guiding material arranged before learning tasks. The purpose of providing advance organizers is to use previously learned materials to explain, integrate, and relate materials to current learning tasks. Before class, teachers can push relevant course resources to students through mobile teaching software, and inform students of the learning objectives, study 
stress, difficulties and other pre-class materials and contents of the new course through the "notice" function, so as to promote the assimilation between old and new knowledge and help students to quickly enter the learning state. Situation -- edify teaching strategy refers to making learners learn in the context of high ideological level and great relaxation by simulating the situation similar to the society or life of learners. Teachers can carry out activities such as drama appreciation, role playing and situation recitation in textbooks. The "activity" function of the class can also be used to carry out various forms of online classroom activities, such as brainstorming, answering questions and voting, etc. Meanwhile, students' activity achievements can be displayed, evaluated and summarized. Collaborative teaching strategy is not only conforms to give priority to in order to teach, and suitable to give priority to in order to learn a kind of teaching strategies, teachers can carry out timely face-to-face classroom discussion, role playing, contests and other activities, can also use "answering questions/discussion", "create group tasks", "brain storm", and other functions to carry out timely online discussion activities, so that the students in the mutual help, competition, discussion, tips, division of labor cooperation on the basis of the solution to the problem of teachers have put forward.

Design of teaching activities. The blended learning activities based on blue ink cloud class mainly include face-to-face teaching, online learning and discussion and interaction, which can be used in combination according to teachers' teaching needs and students' learning needs in the actual teaching process. The mobile hybrid learning activity diagram is shown inFig. 2.

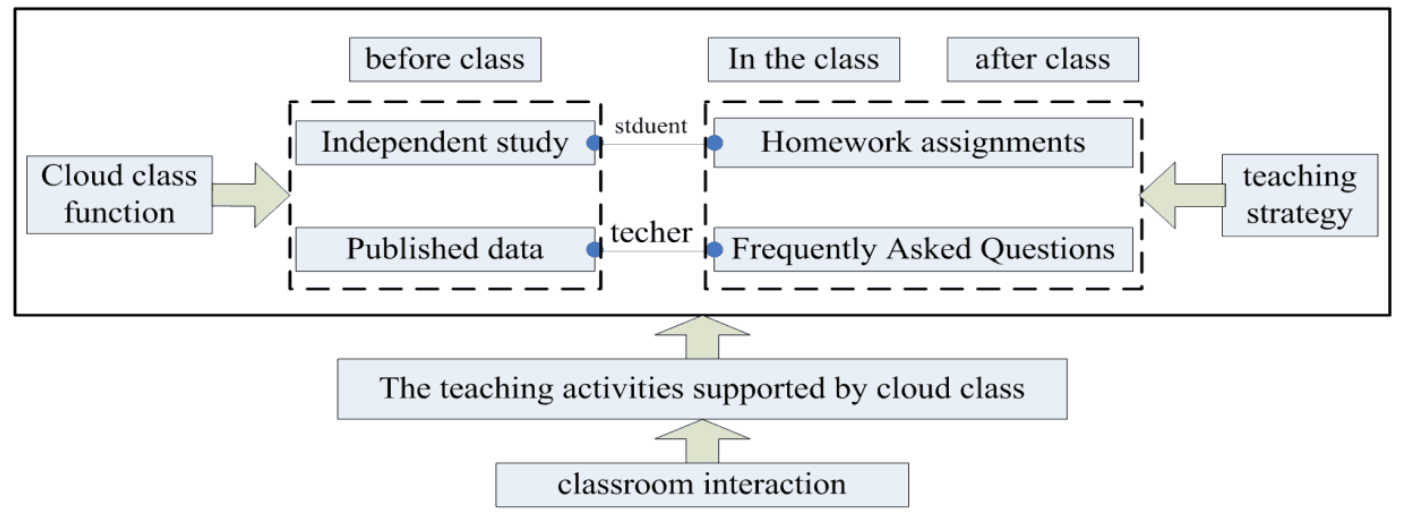

Figure 2.mobile hybrid learning activity block diagram

Hybrid teaching evaluation design. Teaching evaluation is a multi-component evaluation of learners' teaching activities and teaching results, while the mixed teaching pays more attention to process evaluation. Evaluation mainly is aims at the learner learning process before class, class, after class to participate in the activities of teaching evaluation, using the exp gain access to resources before class, class attendance of the experience gained in value, the discussion/answer the number of experience, and won the praise of the experience gained from the experience value, classroom performance value, the experience value obtained after-school activities, such as the experience value reflects the student's learning attitude, the teacher to student's evaluation, students' mutual, classroom learning situation, and online learning activity, etc., can effectively response the students throughout the learning path, objectively reflects the situation of the students throughout the learning process [5].

Teaching effect. Through A semester of practice, it is shown that class A, which USES the blue ink cloud class and adopts the mixed teaching mode, has A remarkable effect, with higher learning interest and enthusiasm, significantly improved cooperative and independent learning ability, especially for students with poor learning foundation. The final course scores of classes A and B are shown in table 1.

Table 1 analysis of examination results of course

\begin{tabular}{|c|c|c|c|c|}
\hline The class & Teaching mode & average & $\begin{array}{c}\text { Excellent rate (out of } \\
90)\end{array}$ & Don't pass \\
\hline A class & Hybrid teaching model & 86.4 & 17.8 & 2.1 \\
\hline B class & $\begin{array}{c}\text { Traditional teaching } \\
\text { model }\end{array}$ & 77.8 & 6.7 & 8.9 \\
\hline
\end{tabular}




\section{Conclusion}

This article use blue ink cloud class mobile teaching software, built a "Internet + " under the background of the real-time interactive teaching mode, the organic combination of existing classroom teaching with virtual class, the organic integration of inside and outside classroom learning activities, and according to different development course and the teaching object of activity curriculum resources, the design course, targeted delivery of teaching resources, stimulate students' interest in learning, improve the teaching effect. At the same time, the "Internet + " technology is used to integrate the process assessment mechanism into the course assessment, improve the teaching evaluation mechanism and supervise students' learning process, which is of certain reference value for deepening the practice of blended teaching.

\section{Acknowledgements}

Jilin Engineering Normal University in 2017: Research on the Dynamic Mechanism and Mode of School Enterprise Cooperation in Application-oriented Universities.

\section{Reference}

[1] Sun zhong, yu jiaxin, wen yuxi, and zhu zheng. The deepening and innovation of mixed learning -- summary of the 8th international conference of mixed learning and education technology international symposium [J]. Beijing: China remote education,2015 (09) :5-9

[2] Du shichun, fu zetian. Mixed learning based on MOOC and its empirical study [J]. Beijing: China dianhua education,2016 (12) :129-133+145.

[3] Zhang qiliang, wang aichun. Research on new hybrid teaching model based on "flipped classroom" [J]. Beijing: modern education technology,2014 (04) :27-32.

[4] Meng tingting. Reflections on the application of the lanmo cloud class in the teaching process [J]. Chengdu city, sichuan province: education,2016(15):114.

[5] Hao lina. Application of the blended teaching model based on the class platform of blue mo yun class in higher vocational organic chemistry teaching [J]. Beijing: occupation,2016(14): 149-150. 